\title{
When a Reappearance Is Old News: Visual Marking Survives Occlusion
}

\author{
Melina A. Kunar, Glyn W. Humphreys, \\ and Kelly J. Smith \\ University of Birmingham
}

Derrick G. Watson
University of Warwick

\begin{abstract}
Performance in a visual search task becomes more efficient if half of the distractors are presented before the rest of the stimuli. This "preview benefit" may partly be due to inhibition of the old (previewed) items. The preview effect is abolished, however, if the old items offset briefly before reappearing (D. G. Watson \& G. W. Humphreys, 1997). The authors examined whether this offset effect still occurred if the old items undergo occlusion. Results show that a preview benefit was found when the old items were occluded but not otherwise, consistent with the idea of top-down attentional inhibition being applied to the old items. The preview benefit is attenuated, however, by movement of the irrelevant stimuli in the displays.
\end{abstract}

The visual world is inundated with a vast range of stimuli. If one were to search every item in every scene, one would waste valuable time and energy on irrelevant distractor items, especially as scenes are constantly being updated through time. There needs to be some way of segregating relevant from irrelevant stimuli. One possible way of doing this is through visual marking (VM).

VM is a mechanism proposed by Watson and Humphreys (1997) for prioritizing the selection of new stimuli by deprioritizing the selection of old ones. In essence, old irrelevant distractor items become inhibited or "marked" and are thus ignored in visual search; as a consequence, there is prioritized detection of new items. Watson and Humphreys investigated VM by comparing three conditions in visual search tasks: single feature, conjunction, and preview search. In the single-feature condition, participants were instructed to search for a blue letter $H$ among blue letter $A s^{1}$ In the conjunction condition, participants were asked to search for a blue letter $H$ among blue $A$ s and green $H$ s (see Treisman \& Gelade, 1980). In the preview condition, green $H$ s were initially presented alone, and then, after a brief period of time, blue $A \mathrm{~s}$ appeared with the target blue $H$ (on target-present trials). Watson and Humphreys found that the search slope for the preview condition was similar to that for the single-feature search, and it was much less than the slope for search on conjunction trials. They concluded that participants searched only the new set of items (i.e., the blue stimuli) and inhibited the old distractors using top-down attentional resources (Watson \& Humphreys, 1997).

Melina A. Kunar, Glyn W. Humphreys, and Kelly J. Smith, Behavioural Brain Sciences Centre, University of Birmingham, Birmingham, England; Derrick G. Watson, Department of Psychology, University of Warwick, Coventry, England.

This work was supported by a Biotechnology and Biological Sciences Research Council studentship to Melina A. Kunar and by grants from the Medical Research Council to Glyn W. Humphreys and the Economic and Social Research Council to Derrick G. Watson.

Correspondence concerning this article should be addressed to Melina A. Kunar, Behavioural Brain Sciences Centre, University of Birmingham, Edgbaston, Birmingham B15 2TT, United Kingdom. E-mail: mak608@ bham.ac.uk
Direct evidence for an inhibitory component to the preview benefit in search comes from studies using a probe dot procedure. Watson and Humphreys (2000) found that detection of a probe dot was impaired when the dot fell at an old (marked) item compared with when it fell at the location of a new item. However, this occurred only when participants engaged in a search task on a majority of trials. When the task changed to probe detection on every trial, there was little difference between probes presented near old compared with new stimuli, though the display conditions were the same as when the probe task was embedded in the search task. Hence inhibition of the probe at old locations was not due to the display conditions but to the search set adopted by participants. Converging evidence for the importance of the search set comes from studies using dual-task interference. Specifically, the magnitude of the preview effect decreases systematically if participants undertake a secondary task when the old distractors are present (Watson \& Humphreys, 1997). Olivers and Humphreys (2002) further showed that the detection of probes at old locations can be improved under secondary task conditions, consistent with fewer resources then being available to inhibit the old items.

If $\mathrm{VM}$ is an ecologically valid mechanism, then it should be sustained through disruptions that are likely to be encountered in the real world. One such disruption is occlusion. Imagine trying to prioritize selection for a predator that might be hidden among a group of zebras as they move across the savannah. If the zebras move behind some bushes and reappear, it would be useful to continue to treat them as "old" objects, so that selection could continue to be prioritized for the "new" predator, should it appear. That is, selection would be optimized by maintaining VM across occlusion. We set out to test this here, and, in doing so, we also investigated the nature of the representations mediating VM. In particular, if VM survives occlusion, then it must be based on relatively high-level representations, for example, on locations or groups of old items coded in three-dimensional space.

\footnotetext{
${ }^{1}$ Such letters are italicized, here and throughout the article text, for clarity; note that in the experiments proper, these letters did not appear in italics.
} 
Previous studies have shown that the visual system can rapidly compensate for occlusion. For example, Kellman and Spelke (1983) found that infants 4 months of age acted as if a rod occluded by a block was continuous, even though the occluded part remained hidden from sight (for converging evidence, see also Baillargeon, 1986; Baillargeon \& DeVos, 1991; Baillargeon \& Graber, 1987; Spelke, Breinlinger, Macomber, \& Jacobson, 1992). Therefore, the visual system learns to assimilate occlusion into the rules of perceptual organization at an early age. This is supported by physiological and behavioral studies with adults. Assad and Maunsell (1995) found that over half the neurons in the posterior parietal cortex are still active when an item is being occluded, despite there being no lower level sensory input. In a behavioral study looking at the spread of illusory color over occluded regions, Davis and Driver (1997) found that attention could be applied to areas behind transparent occluders and areas that have been modally completed, even though they are physically absent. Scholl and Pylyshyn (1999) further found that items could be tracked with no costs after being occluded. Here we ask if the same holds for VM.

The present study investigated whether items still remain inhibited after being occluded, and thus do not interfere with search, when new items are presented. Watson and Humphreys (1997, Experiment 6) found that the preview benefit was abolished when the old items were transiently offset for $250 \mathrm{~ms}$, before being presented again along with the second set of stimuli. However, if this same transient offset occurs but is attributable to occlusion, then is the preview benefit maintained?

It has also been hypothesized that the preview benefit in search is not contingent on the inhibition of old items but is entirely due to bottom-up capture of attention by new luminance increments (see Donk \& Theeuwes, 2001). As a sideline, the present experiments investigated whether this theoretical standpoint can fully explain the preview effect. If luminance increments capture attention, then no preview benefit should be elicited in the occlusion condition as the attentional system should be captured by old items reappearing (and thus showing a luminance onset) after occlusion. In this respect, the occlusion condition should match the transient offset condition reported by Watson and Humphreys (1997, Experiment 6; also replicated here in Experiment 2), when the preview benefit was eliminated (see earlier). Here we ask whether the benefit is abolished if, during the offset period, the old items appear to undergo occlusion. In terms of the transient changes to the displays, the occlusion and offset conditions should be matched. On an onset-capture account, no preview effect should occur. However, if there is inhibition of relatively high-level representations of stimuli that survives occlusion, then a preview effect should be found if old items change transiently but reappear in positions consistent with movement and occlusion.

We report three experiments in the present article. In Experiment 1 we examined performance in preview search when old distractors are occluded by moving blocks prior to the old distractors reappearing simultaneously with the new stimuli. This condition was compared with performance in a nonocclusion condition in which blocks moved in the visual field but did not occlude the old distractors. This experiment assessed whether occlusion of old distractors by the moving blocks disrupted search any more than would be expected from movement of the blocks alone. Experiment 2 compared performance when old items offset without occlusion (the offset condition, as in Watson \& Humphreys, 1997,
Experiment 6) with performance when the old items were occluded by black boxes (so that the luminance changes were matched to those when the old items were offset without occlusion). If VM survives offset conditions consistent with occlusion, then there should be a preview advantage in the occlusion condition compared with the offset condition. Experiment 3 generalizes the occlusion experiments to incorporate two different occlusion time periods. In doing so, we also changed the perceived motion of the occluding blocks and thus the attentive capacity needed to process apparent motion at different speeds. Verstraten, Cavanagh, and Labianca (2000) found that there was a speed limit to attentive tracking of apparent motion, and if this was exceeded, attention could no longer track an object. This implies that increasing the speed of apparent motion also increases the cognitive demands needed to process it. Likewise, fewer resources may be required to process stimuli that have slower rates of apparent motion. Under these circumstances, more resources may be available to inhibit old distractors, and thus old items may be easier to ignore in search. Hence we predict that, if anything, a larger preview benefit should emerge with more slowly moving occluders. This would match prior findings on the effects of secondary tasks on the preview benefit (Humphreys, Watson, \& Jolicœur, 2002; Olivers \& Humphreys, 2002; Watson \& Humphreys, 1997).

\section{Experiment 1: Moving Red Blocks That Either Do or Do Not Occlude Old Green Distractors}

In Experiment 1, we used preview displays containing moving red blocks. In one occlusion condition, these blocks occluded the old green distractors for $300 \mathrm{~ms}$ prior to the search display being presented (containing green and blue letters as well as red blocks). In a nonocclusion condition, the red blocks moved alongside but did not occlude the old green distractors. Does occlusion have any influence on the preview effect?

\section{Method}

Participants. Sixteen participants (9 male and 7 female) were paid to take part as part of a departmental subject day. Their ages ranged from 18 to 30 years (mean age $=21.8$ years), and they were all taken from a population of undergraduates at the University of Birmingham, Birmingham, England. All of the participants had normal or corrected-to-normal vision.

Stimuli. All stimuli were produced by a Turbo Pascal computer program and run on a Pentium computer with VGA graphics card. The dimensions of the letters and red blocks in all of the experiments were 4 $\mathrm{mm}$ wide $\times 8 \mathrm{~mm}$ high. The letters appeared randomly within a $10 \times 10$ matrix. The dimensions of this grid were approximately $90 \mathrm{~mm}$ wide $\times$ $105 \mathrm{~mm}$ high but did not appear on the screen. The RGB values for each color were as follows: blue $(17,41,44)$, green $(3,52,34)$, and red $(50,8$, 12).

In the conjunction and preview conditions, there were 4,8 , or 16 items in total in the search displays. In the single-feature condition, the number of distractors was halved, following the design of Watson and Humphreys (1997). This condition provides a baseline measure of search efficiency when only blue distractor letters are present. If old items can be ignored with perfect efficiency in the preview condition, then slopes of the search functions even with a full set of distractors (old and new) should be the same as that with the half set of distractors (the single-feature baseline). The ratio of red blocks to green $H \mathrm{~s}$ in the conjunction and preview conditions was 1:1. The same number of red blocks was also presented in 


\section{Occlusion Preview Search}

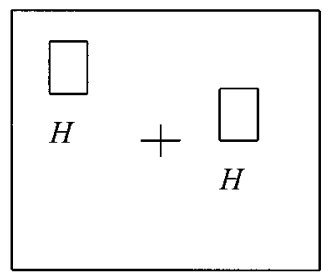

$750 \mathrm{~ms}$

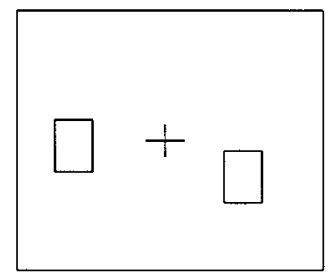

$300 \mathrm{~ms}$

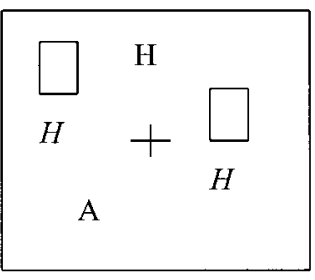

A

Time

Preview Search without occlusion

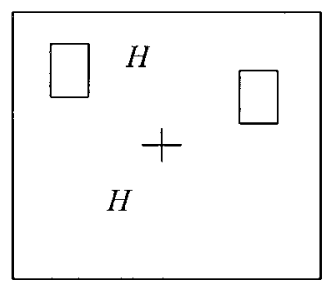

$750 \mathrm{~ms}$

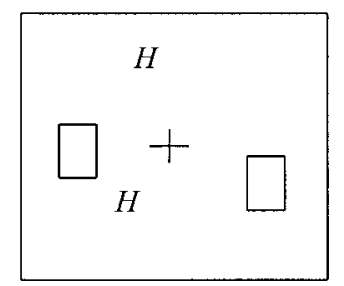

$300 \mathrm{~ms}$
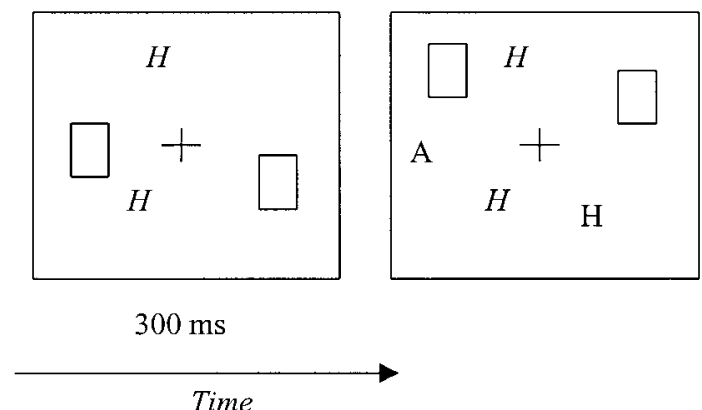

Figure 1. Example displays from Experiment 1. Italic letters here represent green items. (Note that in the experiment proper, the new letters do not appear in italics.)

the single-feature condition (in which the number of red blocks now equaled the number of blue items). The target was present on half of the trials.

Design and procedure. Each participant was asked to complete four conditions: single feature, conjunction, and two preview conditions, in which old green $H$ s either were or were not occluded. Prior to the study, participants were given a practice test with a sample of 30 trials in each condition. In the experiment proper, each search condition was presented in a separate block (for single-feature, conjunction, and preview displays). The experimental blocks each contained 120 trials (20 per display size $\times$ present/absent). The order of the blocks was counterbalanced across participants. The experiment was approximately $45 \mathrm{~min}$ in duration.

In each condition, participants were asked to focus on a white fixation dot in the center of a black screen until the blue items appeared. In all conditions the fixation dot remained on the screen throughout the display. The participants were asked to search for a blue letter $H$ and to respond quickly but accurately by pressing an appropriate key (either " $m$ " or " $z$ "). The participant's dominant hand was always used to indicate target presence, and the other hand indicated target absence.

In the single-feature condition, the trial started with a fixation dot in the center of the screen. After 1,000 ms, red blocks appeared for $750 \mathrm{~ms}$, moved down to a position directly below for $300 \mathrm{~ms}$, and then moved back up to their original position. ${ }^{2}$ At this point blue $A$ s, with or without the blue $H$, were added at random positions within the display. The conjunction condition was similar to the single-feature baseline, except that green $\mathrm{Hs}$ also appeared randomly in the displays.

In the preview condition with occlusion, the trial again started with the fixation dot in the center of the screen. After 1,000 ms, green $H$ s with red blocks positioned vertically above them appeared for $750 \mathrm{~ms}$. The red blocks then moved over the green $H \mathrm{~s}$, covering them for a period of $300 \mathrm{~ms}$ before moving back to their original position. At this point the blue items appeared on the screen, and the green $H$ s were re-presented. In the preview condition with no occlusion, the sole difference was that the red blocks were positioned pseudorandomly in the displays (although they were never vertically above the green $H \mathrm{~s}$ ). The red blocks then moved as before, but this time they did not occlude the green $H$ s, which remained stationary and visible throughout the trial. When the red blocks reached their original position, blue items were added to the screen, and the participants had to ascertain whether there was a blue $H$ present. In each condition, there was a timeout display period of $10,000 \mathrm{~ms}$. The position changes made to the red blocks in the preview condition induced the perception of apparent motion, downward first and then upward (as if the blocks were rebounding). Example displays for the preview conditions are presented in Figure 1.

\section{Results}

Reaction times (RTs) more than three standard deviations away from the mean were eliminated. Figure 2 shows the mean correct RTs as a function of display size and target presence or absence for the preview and single-feature condition. Figure 3 shows the mean correct RTs as a function of display size and target presence or absence for the preview and conjunction conditions. Table 1 dis-

\footnotetext{
${ }^{2}$ In this study the red blocks were presented prior to the search displays in the single-feature and conjunction baselines as well as in the preview conditions, to match conditions as closely as possible.
} 
Absent

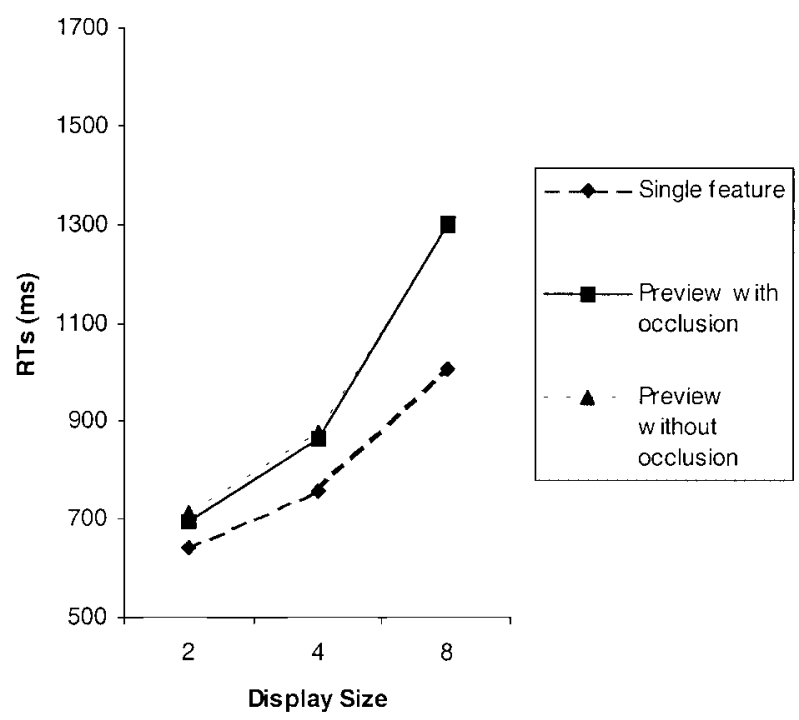

Present

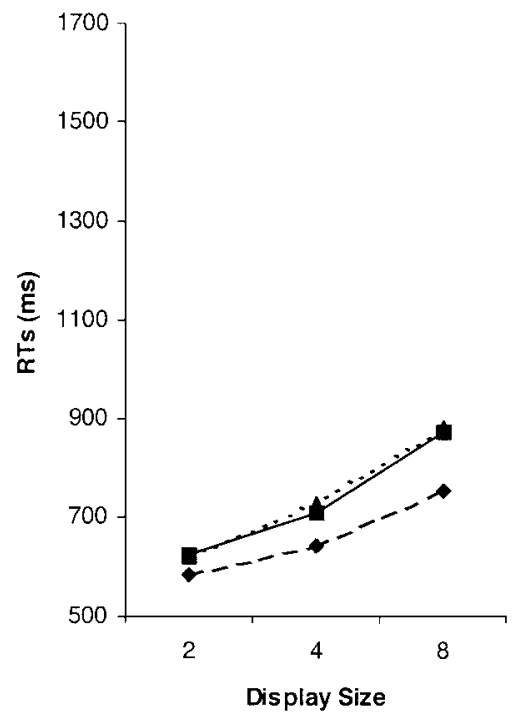

Figure 2. Mean correct reaction times (RTs) in Experiment 1 for the single-feature and preview conditions.

plays the error rates, and descriptive statistics for the search conditions are given in Table 2 .

The RTs for correct trials only for each of the four conditions were entered into a three-way within-subjects analysis of variance (ANOVA) with condition (single feature, conjunction, preview with occlusion, or preview without occlusion), target (absent or present), and display size $(4,8$, or 16$)$ as the main variables. All three main effects were significant: condition, $F(3,45)=33.97$, $p<.01$; target, $F(1,15)=120.13, p<.01$; and display size, $F(2$,
$30)=166.28, p<.01$. Present trials were faster than absent trials, RTs increased as the display size increased, and RTs were fastest in the single-feature condition and slowest in the conjunction search. All the two-way interactions were significant: Condition $\times$ Target, $F(3,45)=13.37, p<.01$; Condition $\times$ Display Size, $F(6$, $90)=30.95, p<.01$; and Target $\times$ Display Size, $F(2,30)=$ $66.30, p<.01$. The three-way interaction was also significant, $F(6,90)=11.50, p<.01$. The three-way interaction was decomposed by means of separate three-way within-subjects ANOVAs,

Absent

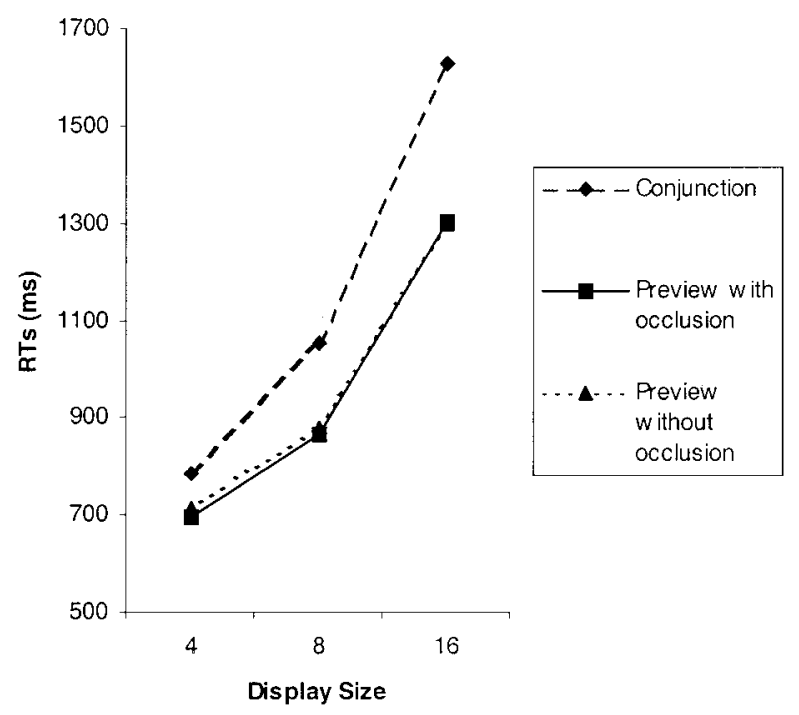

Present

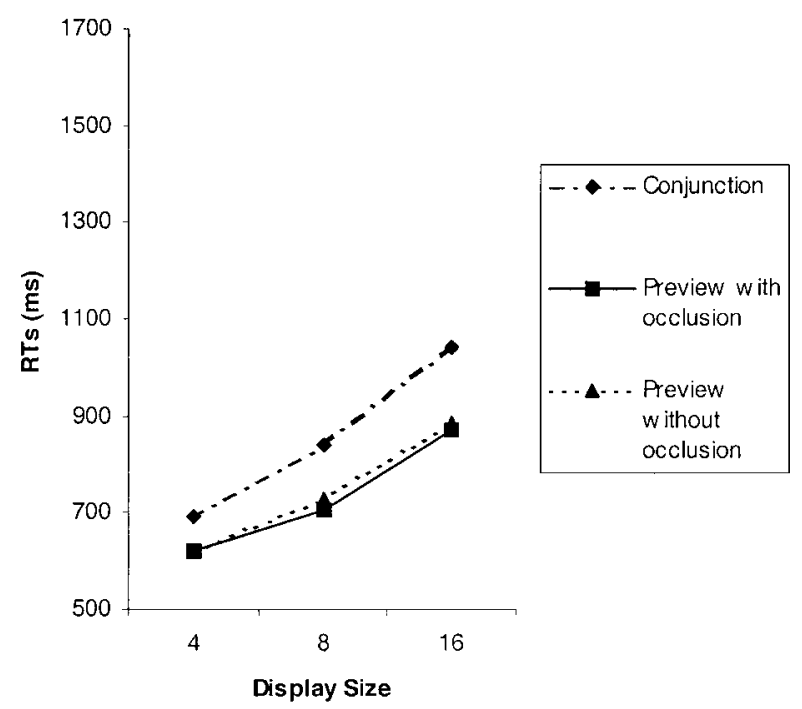

Figure 3. Mean correct reaction times (RTs) in Experiment 1 for the conjunction and preview conditions. 
Table 1

Percentage of Errors in the Different Search Conditions Across Experiments 1-3

\begin{tabular}{|c|c|c|c|c|c|c|}
\hline \multirow[b]{2}{*}{ Experiment and condition } & \multicolumn{3}{|c|}{ Present } & \multicolumn{3}{|c|}{ Absent $^{a}$} \\
\hline & 4 & 8 & 16 & 4 & 8 & 16 \\
\hline \multicolumn{7}{|l|}{ Experiment 1} \\
\hline Single feature & 2.8 & 1.3 & 2.5 & 2.2 & 0.6 & 8.4 \\
\hline Conjunction & 2.5 & 3.8 & 5.3 & 2.5 & 0.6 & 8.8 \\
\hline Preview with occlusion & 4.4 & 2.8 & 4.7 & 3.4 & 0.9 & 9.1 \\
\hline Preview without occlusion & 2.5 & 3.4 & 4.4 & 1.3 & 1.6 & 9.1 \\
\hline \multicolumn{7}{|l|}{ Experiment 2} \\
\hline Single feature & 3.3 & 1.3 & 6.3 & & & \\
\hline Conjunction & 3.8 & 2.5 & 7.3 & & & \\
\hline Standard preview & 2.8 & 2.5 & 7.8 & & & \\
\hline Offset preview & 2.3 & 1.3 & 6.5 & & & \\
\hline Occlusion preview & 3.8 & 2.5 & 6.3 & & & \\
\hline \multicolumn{7}{|l|}{ Experiment 3a } \\
\hline Single feature & 2.5 & 3.5 & 10.5 & & & \\
\hline Conjunction & 1.0 & 1.5 & 9.0 & & & \\
\hline Standard preview & 3.0 & 1.5 & 7.0 & & & \\
\hline Occlusion preview & 4.5 & 2.5 & 5.0 & & & \\
\hline \multicolumn{7}{|l|}{ Experiment $3 \mathrm{~b}$} \\
\hline Single feature & 3.3 & 2.5 & 5.0 & & & \\
\hline Conjunction & 2.5 & 0.8 & 4.2 & & & \\
\hline Standard preview & 1.7 & 2.5 & 7.5 & & & \\
\hline Occlusion preview & 2.5 & 4.2 & 5.8 & & & \\
\hline
\end{tabular}

${ }^{a}$ Absent trials are not applicable for Experiments 2, 3a, and $3 \mathrm{~b}$.

comparing the preview conditions with each other and with the two baseline conditions.

Preview with occlusion condition versus preview condition without occlusion. The two preview conditions were initially compared together in a three-way repeated measures ANOVA. There were reliable main effects of target, $F(1,15)=74.26, p<$ .01 , in which RTs were faster on present than on absent trials, and of display size, $F(2,30)=114.02, p<.01$, in which RTs increased with display size. The Target $\times$ Display Size interaction was also significant, $F(2,30)=48.60, p<.01$. RTs increased more on absent than on present trials as the display size increased. However, there was no significant main effect of condition, $F(1$, $15)=0.2, n s$, and there were no interactions involving this variable. Occlusion and local luminance (contrast) change had no effect on performance. The preview effect of each condition was then individually compared with data from each baseline.

Preview with occlusion versus single-feature baseline. RTs were faster overall in the single-feature condition than in the preview condition, $F(1,15)=30.87, p<.01$; present trials were faster than absent trials, $F(1,15)=87.31, p<.01$; and RTs increased with display size, $F(2,30)=135.66, p<.01$. There were also significant interactions: Condition $\times$ Target, $F(1,15)=$ $10.67, p<.01$; Condition $\times$ Display Size, $F(2,30)=27.41, p<$ .01 ; Target $\times$ Display Size, $F(2,30)=42.95, p<.01$; and Condition $\times$ Target $\times$ Display Size, $F(2,30)=5.58, p<.01$. The effect of display size was larger in the preview than in the singlefeature condition, particularly on absent trials. However, even for present trials alone, there were reliable main effects of condition, $F(1,15)=29.70, p<.01$, and display size, $F(2,30)=160.98, p$ $<$.01. There was also a significant interaction between condition and display size, $F(2,30)=11.88, p<.01$. RTs were affected less in the single-feature condition than in the preview condition by increasing display sizes.

Preview with occlusion versus conjunction baseline. All three main effects were significant: RTs were faster in the preview condition than in the conjunction condition, $F(1,15)=23.10, p<$ .01 ; present trials were faster than absent ones, $F(1,15)=107.94$, $p<.01$; and RTs increased with display size, $F(2,30)=165.05$, $p<.01$. There were also significant interactions: Condition $\times$ Target, $F(1,15)=8.74, p<.01$; Condition $\times$ Display Size, $F(2$, $30)=34.07, p<.01$; Target $\times$ Display Size, $F(2,30)=59.95$, $p<.01$; and Condition $\times$ Target $\times$ Display Size, $F(2,30)=$ $15.84, p<.01$. The effects of display size were greater in the conjunction condition than in the preview condition, with absent trials showing the largest effects. Taking present trials alone, there were significant main effects of condition, $F(1,15)=18.34, p<$ .01 , and display size, $F(2,30)=120.87, p<.01$. The interaction between Condition $\times$ Display Size was also significant, $F(2$, $30)=6.00, p<.01$. RTs were affected less in the preview than in the conjunction condition by increasing display size.

Preview with no occlusion versus single-feature baseline. RTs were faster overall in the single-feature condition than in the preview condition, $F(1,15)=16.85, p<.01$; present trials were faster than absent ones, $F(1,15)=101.88, p<.01$; and RTs increased with display size, $F(2,30)=123.73, p<.01$. There were also significant interactions: Condition $\times$ Target, $F(1,15)=$ $11.57, p<.01$; Condition $\times$ Display Size, $F(2,30)=21.97, p<$ .01 ; Target $\times$ Display Size, $F(2,30)=46.88, p<.01$; and Condition $\times$ Target $\times$ Display Size, $F(2,30)=10.10, p<.01$. The effect of display size was larger in the preview than in the single-feature condition, particularly on absent trials. However, even for present trials alone, there were reliable main effects of condition, $F(1,15)=13.98, p<.01$, and display size, $F(2,30)=$

Table 2

Descriptive Statistics for the Search Functions in Experiment 1

\begin{tabular}{|c|c|c|c|c|c|c|c|c|}
\hline \multirow[b]{2}{*}{ Measure } & \multicolumn{2}{|c|}{ Single feature } & \multicolumn{2}{|c|}{ Conjunction } & \multicolumn{2}{|c|}{$\begin{array}{l}\text { Preview with } \\
\text { occlusion }\end{array}$} & \multicolumn{2}{|c|}{$\begin{array}{l}\text { Preview with } \\
\text { no occlusion }\end{array}$} \\
\hline & Present & Absent & Present & Absent & Present & Absent & Present & Absent \\
\hline Slope (ms/item) & 14.0 & 30.9 & 28.5 & 70.4 & 20.9 & 51.1 & 21.5 & 49.5 \\
\hline Intercept (ms) & 528 & 516 & 594 & 499 & 539 & 479 & 543 & 503 \\
\hline Mean RT (ms) & 659 & 804 & 859 & 1,155 & 735 & 956 & 744 & 964 \\
\hline
\end{tabular}

Note. $\quad \mathrm{RT}=$ reaction time. 
166.70, $p<.01$. There was also a significant interaction between condition and display size, $F(2,30)=8.03, p<.01$. RTs were affected less in the single-feature condition than in the preview condition by increasing display sizes.

Preview with no occlusion versus conjunction baseline. All three main effects were significant: RTs were faster in the preview condition than in the conjunction condition, $F(1,15)=27.54, p<$ .01 ; present trials were faster than absent ones, $F(1,15)=126.62$, $p<.01$; and RTs increased with display size, $F(2,30)=167.48$, $p<.01$. There were also significant interactions: Condition $\times$ Target, $F(1,15)=7.16, p<.05$; Condition $\times$ Display Size, $F(2$, $30)=16.90, p<.01$; Target $\times$ Display Size, $F(2,30)=74.34$, $p<.01$; and Condition $\times$ Target $\times$ Display Size, $F(2,30)=7.51$, $p<.01$. The effects of display size were greater in the conjunction condition than in the preview condition, with absent trials showing the largest effects. Taking present trials alone, there were significant main effects of condition, $F(1,15)=28.61, p<.01$, and display size, $F(2,30)=155.25, p<.01$. The interaction between Condition $\times$ Display size was also significant, $F(2,30)=4.70, p$ $<.05$. RTs were affected less in the preview than in the conjunction condition by increasing display size.

Errors. The error rates were generally low and followed the same trends as the RT data. These data were not analyzed further.

\section{Discussion}

Search performance was more efficient in the occlusion preview condition than in the conjunction search condition; overall, RTs were reduced and the effects of display size on search were less. This benefit, from a preview of the green $H$ distractors, occurred even though these distractors were occluded by the moving red blocks for $300 \mathrm{~ms}$ prior to the blue letters being presented. These data are consistent with an account of VM even under conditions of occlusion. According to this account, the old green distractors are inhibited to help prioritize the selection of the new target. This inhibition is maintained even though the old items undergo occlusion.

However, it is also the case that performance in the occlusion preview condition was not as efficient as in the single-feature baseline. In previous studies, using similar displays and preview durations, search in the preview condition has been as efficient as this baseline (see Watson \& Humphreys, 1997). It may be, then, that inhibition of the old green distractors was reduced when they underwent occlusion. However, this seems unlikely as the preview condition with occlusion showed the same "partial" preview effect as that seen in the preview condition with no occlusion. The comparison between these conditions in fact suggests that the opposite is true, as marking seems to operate across occlusion because search did not differ across the occlusion and nonocclusion conditions. Alternatively, some other factor may have reduced search efficiency in the preview condition. For example, the moving red blocks themselves may attract attention to some degree, or attention may be required for the perception of the long-range apparent motion present when the red blocks moved (e.g., Cavanagh, 1991; Horowitz \& Treisman, 1994). We used conditions likely to involve long-range apparent motion (e.g., with separations of 18 pixels between successive presentations of red blocks and movement intervals of $300 \mathrm{~ms}$ ). If attentional capacity is either captured or consumed by the moving red blocks, then fewer resources may be available to inhibit the old distractors. The preview effect may consequently be weakened. Studies of dualtask interference on preview effects in search fit with this proposal. Watson and Humphreys (1997, Experiments 8 and 9) showed that the preview benefit was reduced when participants attended to a series of numbers presented at fixation while the old items were exposed, and Humphreys et al. (2002) even showed similar results when secondary task stimuli are presented auditorily (so the interference is not visual in nature). To account for their results, Watson and Humphreys (1997) suggested that, under dual-task conditions, there was weaker inhibition of old distractors owing to fewer attentional resources being available. The effect of the movement of the blocks on the preview benefit was further tested in Experiment 3 (see later), in which the apparent motion of the occluding blocks was relatively "slowed" or "speeded" by altering the timing conditions. If processing the apparent motion uses cognitive resources needed for inhibitory filtering, then perhaps by reducing the cognitive load needed to process the motion of the red blocks (by virtually slowing the movement; see Verstraten et al., 2000), then the preview benefit will in turn become more efficient.

\section{Experiment 2: Effect of Occlusion Versus Complete Offset of Old Distractors}

Experiment 2 provides a further test of whether VM survives occlusion by using matched luminance/contrast changes across preview, occlusion, and offset conditions. Whereas in Experiment 1 we used a condition that minimized local luminance/contrast changes at old locations, in Experiment 2 we induced luminance/ contrast changes but matched them in occlusion and offset conditions. Watson and Humphreys (1997, Experiment 6) reported one study in which old distractors were offset for a 250-ms interval prior to the exposure of new stimuli. The preview effect was completely eliminated in this offset condition. We ask whether luminance/contrast changes sufficient to abolish the preview effect under offset conditions give rise to a partial preview effect when displays are consistent with occlusion. Here, Experiment 2 replicated the results of Watson and Humphreys (1997), with old green distractors offsetting to a black background for $300 \mathrm{~ms}$ before reappearing with the exposure of the new blue items, and compared the results with a condition in which occlusion conditions accounted for the offsetting green stimuli. In this condition, black boxes (defined by a thin, white perimeter line) were used to occlude the old green items for the same duration. With these stimuli, the local luminance/contrast changes created by occlusion are the same as those created by offsets of the old items. Example displays are shown in Figure 4.

\section{Method}

Participants. Twenty-one students ( 8 male and 13 female) ages 19 to 33 years (mean age $=22.1$ years) were paid to serve as participants. All were undergraduates at the University of Birmingham and had selfreported normal or corrected-to-normal vision.

Stimuli. The stimuli had changed slightly from Experiment 1 . Each condition again consisted of finding a blue $H$ among distractor items of green $H \mathrm{~s}$ and blue $A$ s (depending on the condition), but this time the target was always present. Here participants had to decide whether the bar of the blue $H$ was higher than the midpoint of the $y$-axis or lower than the midpoint. The surrounding green $H$ distractors also had bars in a position above the vertical midpoint or below it, to preserve conjunction conditions. A pilot test using these stimuli found that the relationships between the 
Standard Preview Search

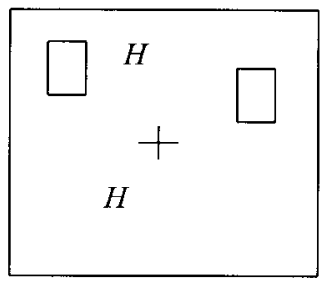

$750 \mathrm{~ms}$
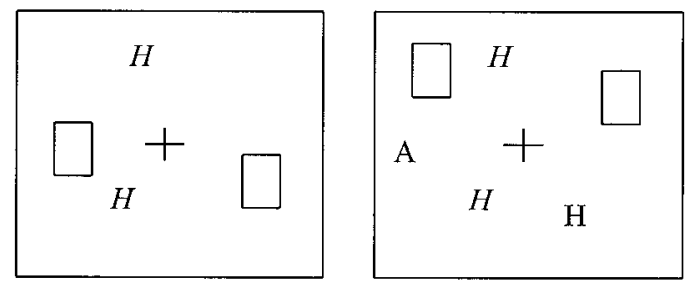

$300 \mathrm{~ms}$ (Experiment 2)

$100 \mathrm{~ms}$ (Experiment 3a)

$1000 \mathrm{~ms}$ (Experiment 3b)

Time

“Offset" Preview Search

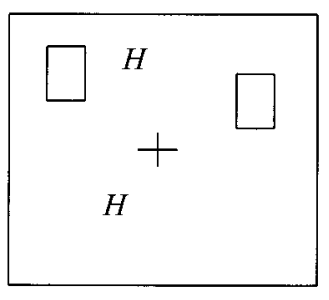

$750 \mathrm{~ms}$

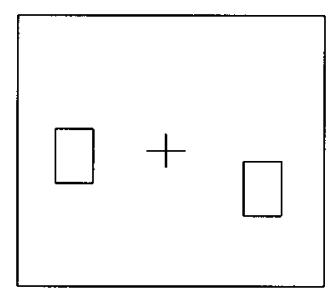

$300 \mathrm{~ms}$

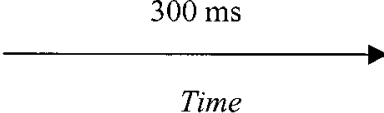

\section{Occlusion Preview Search}

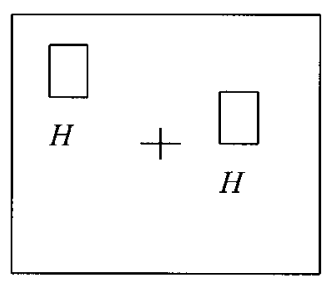

$750 \mathrm{~ms}$
Time
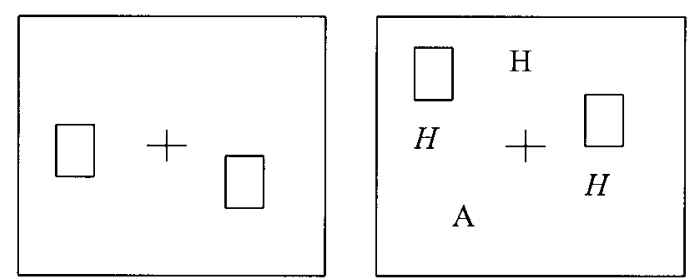

$300 \mathrm{~ms}$ (Experiment 2)

$100 \mathrm{~ms}$ (Experiment 3a)

$1000 \mathrm{~ms}$ (Experiment 3b)
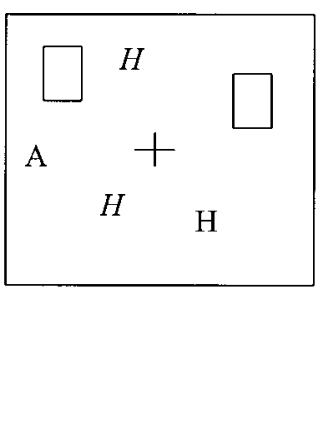

\section{Time}

Figure 4. Example displays from Experiment 2. Italic letters here represent green items. (Note that in the experiment proper, the new letters do not appear in italics.)

search slopes of the single-feature, conjunction, and standard preview conditions were preserved in respect to Watson and Humphreys (1997) original findings (i.e., the slope for search in the preview condition was the same as in the single-feature baseline and less than that in the conjunction condition).

Design and procedure. To maximize the number of trials on which critical data were collected, we changed the task from a present/absent decision to a target discrimination decision, in which the target was present in $100 \%$ of the trials. The response made by the participant was the same as in Experiment 1 (i.e., either pressing the key "m" or " $z$ "), but this time, instead of determining whether the target was absent or present, participants had to determine whether the target had a high or low horizontal bar.
Response keys were counterbalanced across participants. In each condition the target item was again a blue $H$, and the distractor items were composed of blue $\mathrm{As}$ and green $\mathrm{Hs}$, depending on the condition. ${ }^{3}$

\footnotetext{
${ }^{3}$ In several studies conducted using forced-choice target discrimination responses, rather than present-absent responses, we have found almost exactly the same results as obtained on present trials in search (e.g., Olivers \& Humphreys, 2002). It is highly unlikely that this small change in the procedure here had any substantial impact on performance.
} 
There were five conditions in this experiment: a single-feature, a conjunction, a "standard" preview, an offset, and an occlusion condition. In the single-feature condition, a fixation cross was presented on the screen for $1,000 \mathrm{~ms}$, followed by black blocks. These remained on the screen for 750 $\mathrm{ms}$ before moving for $300 \mathrm{~ms}$ to a position one place in the location matrix below their original position and then returning to their original position. At this point, blue $A$ s and the blue $H$ appeared on the screen alongside the black blocks. Here participants were asked to determine whether the target had a high or low bar and respond accordingly. The conjunction condition was similar to the single-feature condition, except that green $H$ s were presented with the blue items in the search displays.

In the standard preview condition, a white fixation cross was presented for 1,000 ms before black blocks and green $H$ s were placed randomly in the field for $750 \mathrm{~ms}$. The black blocks then moved to a position directly below in the matrix for $300 \mathrm{~ms}$ before returning to their original positions. At this point, blue items appeared on the screen and participants began their search. In this condition the green $H$ s always remained visible.

In the offset condition, the fixation cross appeared for 1,000 ms followed by the green $H \mathrm{~s}$ and black blocks again for $750 \mathrm{~ms}$. The black blocks moved to a position below, and at the same time the green $H$ s offset from the screen. After $300 \mathrm{~ms}$ the black blocks moved back up to their original position, and the green $H$ s reappeared in their original positions. At the same time, blue items appeared on the screen. For this condition the green pixels making up the old distractors were replaced with black pixels, matching the black background.

Finally, in the occlusion condition, the fixation cross was followed by green $\mathrm{Hs}$ with black blocks positioned directly above them. These remained on screen for $750 \mathrm{~ms}$ before the black blocks moved down to cover the green $H$ s for $300 \mathrm{~ms}$ before moving back up to their original position. At this point, blue items (blue $A$ s and a blue $H$ ) appeared on the screen, and participants were asked to respond to the blue $H$.

Each participant was given a short set of practice trials before each condition, and the whole experiment took approximately $45 \mathrm{~min}$. Each experimental condition appeared in independent blocks, which were counterbalanced across participants.

\section{Results}

One participant was dropped from the analysis because of high errors (over $30 \%$ in one condition). Figure 5 shows the mean correct RTs as a function of display size for the single-feature and preview conditions in Experiment 2. Figure 6 shows the same but for the conjunction and preview conditions. Error rates are given in Table 1 and full descriptive statistics in Table 3.

As in Experiment 1, the mean correct RTs for the preview conditions were compared with those from the two baselines using separate two-way within-subjects ANOVAs.

Preview versus single-feature baseline. There was no significant main effect of condition, $F(1,19)=2.14, n s$, but the main effect of display size, $F(2,38)=135.98, p<.01$, was significant. There was also a significant interaction of condition and display size, $F(2,38)=14.05, p<.01$. There was a greater increase in RTs with display size in the preview than in the single-feature condition.

Preview versus conjunction baseline. The main effects of condition, $F(1,19)=16.26, p<.01$, and display size, $F(2,38)=$ $122.90, p<.01$, were significant, as was the interaction between condition and display size, $F(2,38)=3.26, p<.05$. RTs showed a larger increase with display size in the conjunction condition than in the preview condition.

Offset versus single-feature baseline. The main effects of condition, $F(1,19)=12.59, p<.01$, and display size, $F(2,38)=$

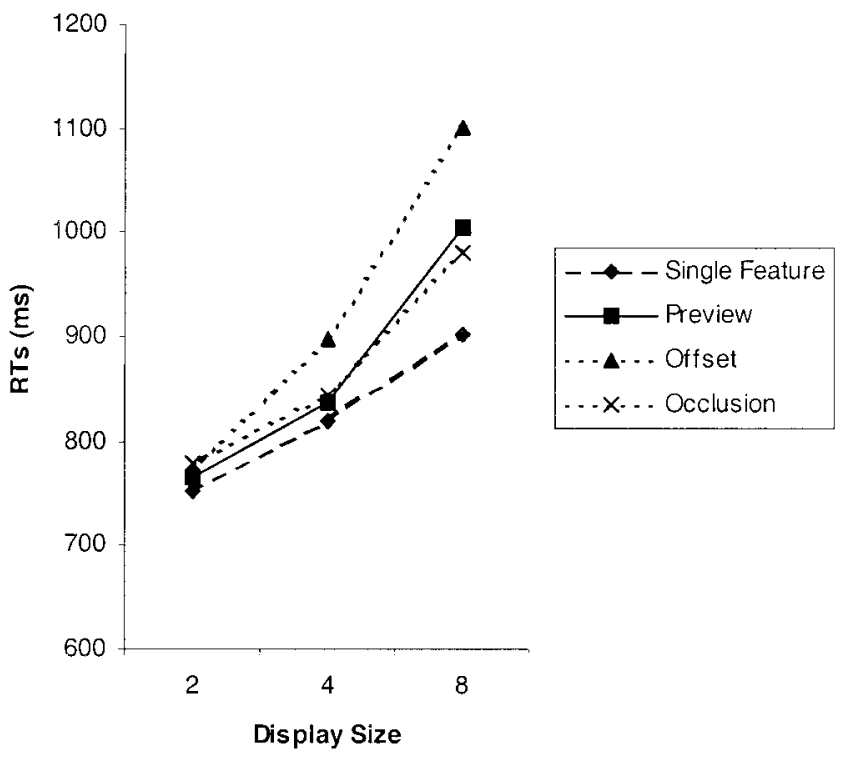

Figure 5. Mean correct reaction times (RTs) in Experiment 2 for the single-feature and preview conditions.

$151.00, p<.01$, were significant. There was also a significant interaction between condition and display size, $F(2,38)=30.43$, $p<.01$. The effects of display size were larger in the offset condition.

Offset versus conjunction baseline. There was only a reliable effect of display size, $F(2,38)=161.23, p<.01$. There was no significant main effect of condition, $F(1,19)=1.82, n s$, and no interaction of Condition $\times$ Display Size, $F(2,38)=0.10, n s$.

Occlusion versus single-feature search. The main effects of condition, $F(1,19)=6.89, p<.05$, and display size, $F(2,38)=$ $101.74, p<.01$, were significant, as was the interaction between condition and display size, $F(2,38)=6.04, p<.01$. The effects of display size were larger in the occlusion condition than in the single-feature baseline.

Occlusion versus conjunction baseline. The main effects of condition, $F(1,19)=9.26, p<.01$, and display size, $F(2,38)=$ $143.62, p<.01$, were significant. There was also a significant interaction between condition and display size, $F(2,38)=5.29, p$ $<.01$, in which RTs were faster in the preview condition than in the conjunction condition. Search in the preview condition was more efficient than in the conjunction baseline.

RTs in the critical experimental conditions (standard preview, offset, and occlusion) were also compared directly.

Preview versus offset. There was a reliable main effect of display size, $F(2,38)=152.86, p<.01$, but not of condition, $F(1$, $19)=3.62$, ns. However, there was a significant Condition $\times$ Display Size interaction, $F(2,38)=6.52, p<.01$. Display size effects were larger in the offset condition than in the standard preview condition.

Occlusion versus offset. The main effects of condition, $F(1$, $19)=4.93, p<.05$, and display size, $F(2,38)=150.21, p<.01$, were significant. There was also a significant interaction between condition and display size, $F(2,38)=10.84, p<.01$, in which RTs were faster in the occlusion condition than in the offset condition, particularly at the larger display sizes. 


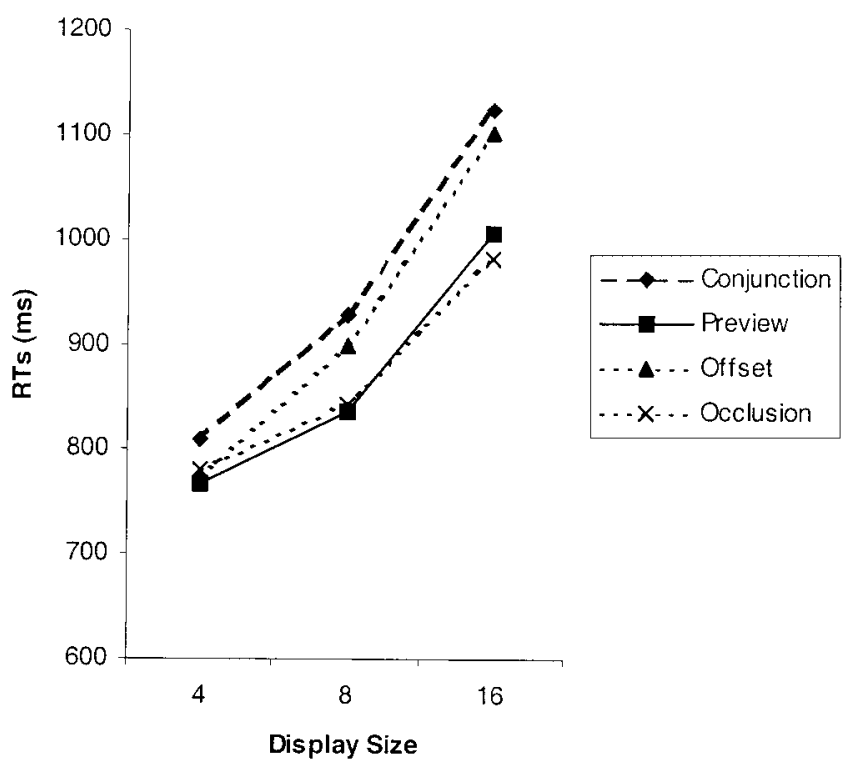

Figure 6. Mean correct reaction times (RTs) in Experiment 2 for the conjunction and preview conditions.

Preview versus occlusion. There was only a reliable effect of display size, $F(2,38)=152.57, p<.01$. There was no significant main effect of condition, $F(1,19)=0.00, n s$, and no interaction of Condition $\times$ Display Size, $F(2,38)=0.31, n s$.

\section{Discussion}

In the offset and standard preview conditions comparison, the pattern of the results replicates the data reported by Watson and Humphreys (1997). In the standard preview condition, search was more efficient than in the appropriate conjunction baseline condition. However, this preview benefit was eliminated in the offset condition. In other unpublished studies, we have replicated these results even when stimuli were presented up to three times with 750 -ms exposures of old items followed by 250 -ms offset durations. Even here there was no evidence of a preview benefit. Critically, the data show that the offset, as well as the reappearance of the old items along with the new stimuli, is disruptive for search.

However, when the offset of old items can be accounted for by occlusion, then a preview benefit was obtained. The critical aspect of Experiment 2 is that the local luminance and contrast changes generated from occlusion by black blocks were the same as those changes used in the offset condition, yet only in the offset condi- tion was the preview benefit abolished. The timing conditions for occluded previews were also matched to those in the offset condition. These qualitative changes in performance in the offset and occlusion conditions provide evidence that high-level representations of the displays modulate preview benefits in search and that local changes in luminance and contrast are not critical. We suggest that this is because inhibitory marking contributes to the preview advantage. The data indicate that inhibitory marking is applied to high-level representations of old items, which are maintained even when these items are occluded. The effectiveness of search can be reduced, however, when long-range apparent motion is perceived in the first display. This takes away resources from the marking process. In the General Discussion, we return to discuss the implications of this result for other accounts of the preview benefit.

\section{Experiment 3: Varying Occlusion Time Periods and Apparent Speed of the Blocks}

If $\mathrm{VM}$ is an ecologically valid mechanism and can survive occlusion, it should be able to survive a number of occlusion time periods (not just $300 \mathrm{~ms}$ !). In Experiment 3 we attempted to extend the earlier occlusion experiments by varying the occlusion times used. In this way the apparent speed of the blocks also changed (i.e., as the occlusion time decreased, so the blocks appeared to move faster). If attentional resources are consumed in computing apparent motion (Cavanagh, 1991; Horowitz \& Treisman, 1994), and if attentional demands are particularly severe for high-motion speeds (Verstraten et al., 2000), then the preview benefit may (if anything) be greatest when there is relatively slow apparent motion (and occlusion occurs). We expect the preview effect to be largest when participants can marshal maximal resources to inhibit the old items (Humphreys et al., 2002; Watson \& Humphreys, 1997).

\section{Experiment 3a: Occluding Items for $100 \mathrm{~ms}$}

Experiment 3a investigated whether marking can survive if items are occluded for a period of $100 \mathrm{~ms}$. With a reduced interstimulus interval between presentations of the blocks, the movement of the blocks appeared faster. Example displays for the preview and occlusion conditions are shown in Figure 4.

\section{Method}

Participants. Eleven students (6 male and 5 female) ages 20 to 33 years (mean age $=25.4$ years) were paid to serve as participants. All were undergraduates at the University of Birmingham and had self-reported normal or corrected-to-normal vision.

Stimuli. The stimuli were the same as those in Experiment 2.

Table 3

Descriptive Statistics for the Search Functions in Experiment 2

\begin{tabular}{lccccc}
\hline \multicolumn{1}{c}{ Measure } & $\begin{array}{c}\text { Single } \\
\text { feature }\end{array}$ & Conjunction & $\begin{array}{c}\text { Standard } \\
\text { preview }\end{array}$ & $\begin{array}{c}\text { Offset } \\
\text { preview }\end{array}$ & $\begin{array}{c}\text { Occlusion } \\
\text { preview }\end{array}$ \\
\hline Slope (ms/item) & 12.1 & 26.0 & 20.1 & 27.3 & 16.8 \\
Intercept (ms) & 713 & 711 & 682 & 669 & 712 \\
Mean RT (ms) & 825 & 954 & 870 & 924 & 868 \\
\hline
\end{tabular}

Note. $\quad \mathrm{RT}=$ reaction time. 
Design and procedure. There were four conditions: a single-feature, a conjunction, a standard preview, and an occlusion condition. In the singlefeature condition, a fixation cross was presented on the screen for 1,000 $\mathrm{ms}$, followed by black blocks. These remained on the screen for $750 \mathrm{~ms}$ before moving for $100 \mathrm{~ms}$ to a position one place in the location matrix below their original position and then returning to their original position. At this point, blue $A$ s and the blue $H$ appeared on the screen alongside the black blocks. Here participants were asked to determine whether the target had a high or low bar and respond accordingly. The conjunction condition was similar to the single-feature condition, except that green $H$ s were presented with the blue items in the search displays.

In the standard preview condition, a white fixation cross was presented for 1,000 ms before black blocks and green $H$ s were placed randomly in the field for $750 \mathrm{~ms}$. The black blocks then moved to a position directly below in the matrix for $100 \mathrm{~ms}$ before returning to their original positions. At this point, blue items appeared on the screen, and participants began their search. In this condition the green $H$ s always remained visible.

Finally, in the occlusion condition, the fixation cross was followed by green $H$ s with black blocks positioned directly above them. These remained on screen for $750 \mathrm{~ms}$ before the black blocks moved down to cover the green $H$ s for $100 \mathrm{~ms}$ before moving back up to their original position. At this point, blue items (blue $A$ s and a blue $H$ ) appeared on the screen, and participants were asked to respond to the blue $H$.

Each participant was given a short set of practice trials before each condition, and the whole experiment took approximately $30 \mathrm{~min}$. Each experimental condition appeared in independent blocks, which were counterbalanced across participants.

\section{Results}

One participant was dropped from the analysis because of high errors (over $20 \%$ in one condition). Figure 7 shows the mean correct RTs as a function of display size for the single-feature and preview conditions in Experiment 3a, and Figure 8 shows the same for conjunction and preview conditions. Error rates are given in Table 1 and full descriptive statistics in Table 4.

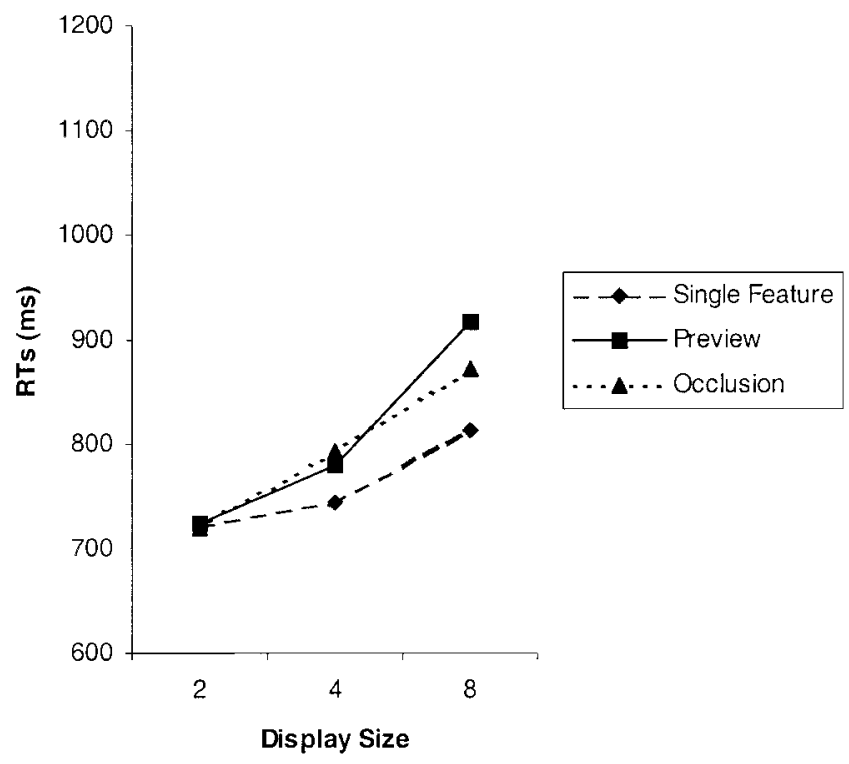

Figure 7. Mean correct reaction times (RTs) in Experiment 3a for the single-feature and preview conditions.

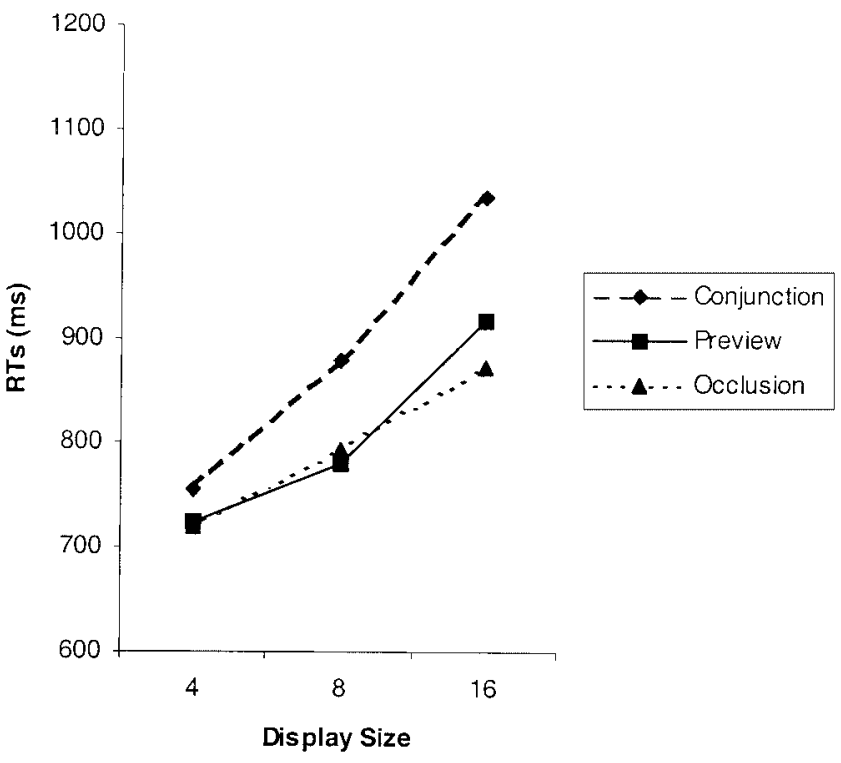

Figure 8. Mean correct reaction times (RTs) in Experiment 3a for the conjunction and preview conditions.

Preview versus single-feature baseline. There was a significant main effect of condition, $F(1,9)=17.42, p<.01$, and of display size, $F(2,18)=58.06, p<.01$. There was also a significant interaction of condition and display size, $F(2,18)=15.94, p$ $<.01$. There was a greater increase in RTs with display size in the preview than in the single-feature condition.

Preview versus conjunction baseline. The main effects of condition, $F(1,9)=16.75, p<.01$, and display size, $F(2,18)=$ $110.16, p<.01$, were significant, as was the interaction between condition and display size, $F(2,18)=9.78, p<.01$. RTs showed a larger increase with display size in the conjunction condition than in the preview condition.

Occlusion versus single-feature search. There was no significant main effect of condition, $F(1,9)=3.90, n s$, but there was one of display size, $F(2,18)=26.19, p<.01$. There was also a significant interaction between condition and display size, $F(2$, $18)=6.33, p<.01$. The effects of display size were larger in the occlusion condition than in the single-feature baseline.

Occlusion versus conjunction baseline. The main effects of condition, $F(1,9)=32.76, p<.01$, and display size, $F(2,18)=$ $72.00, p<.01$, were significant. There was also a significant interaction between condition and display size, $F(2,18)=14.61$, $p<.01$, in which RTs were faster in the preview condition than in the conjunction condition, particularly at the larger display sizes.

Preview versus occlusion. There was a reliable effect of display size, $F(2,18)=47.42, p<0.01$, and of Condition $\times$ Display Size, $F(2,18)=5.80, p<.05$, in which RTs were faster in the occlusion condition than in the preview condition.

\section{Discussion}

Both the standard preview condition and the occlusion condition were more efficient, in terms of search slopes, than the conjunction baseline condition, but neither was as efficient as the single-feature baseline. As in Experiments 1 and 2, a partial preview advantage 
Table 4

Descriptive Statistics for the Search Functions in Experiment $3 a$

\begin{tabular}{lcccc}
\hline \multicolumn{1}{c}{ Measure } & Single feature & Conjunction & $\begin{array}{c}\text { Standard } \\
\text { preview }\end{array}$ & $\begin{array}{c}\text { Occlusion } \\
\text { preview }\end{array}$ \\
\hline Slope (ms/item) & 7.8 & 22.7 & 16.1 & 12.2 \\
Intercept (ms) & 688 & 678 & 657 & 682 \\
Mean RT (ms) & 760 & 890 & 807 & 796 \\
\hline
\end{tabular}

Note. $\quad \mathrm{RT}=$ reaction time.

was established. This again indicates VM can survive occlusion, even with small intervals of occlusion time. However, when the standard preview and the occlusion conditions were compared, it was found that the occlusion condition showed a more efficient search slope in comparison with the preview condition. At present, it is not clear why this result occurred, although it is at least in the direction in which occlusion is not disruptive to search. In Experiment $3 \mathrm{~b}$, we generalized this result further, but now using a longer occlusion period (1,000 ms) and consequently slow apparent motion. Example displays are shown in Figure 4.

\section{Experiment 3b: Occluding Items for $1,000 \mathrm{~ms}$}

Method

Participants. Six students ( 3 male and 3 female) ages 20 to 33 years (mean age $=25.0$ years) were paid to serve as participants. All were undergraduates at the University of Birmingham and had self-reported normal or corrected-to-normal vision.

Stimuli. The stimuli were the same as those in Experiment 2.

Design and procedure. These were the same as in Experiment 3a, except that now items were occluded for $1,000 \mathrm{~ms}$ instead of $100 \mathrm{~ms}$.

\section{Results}

Figure 9 shows the mean correct RTs as a function of display size for the single-feature and preview conditions in Experiment $3 \mathrm{~b}$, and Figure 10 shows the same for the conjunction and preview conditions. The error rates are given in Table 1 and full descriptive statistics in Table 5.

Preview versus single-feature baseline. There was a significant main effect of condition, $F(1,5)=8.09, p<.05$, and of display size, $F(2,10)=13.89, p<.01$. However, there was no significant interaction of condition and display size, $F(2,10)=$ $0.82, n s$.

Preview versus conjunction baseline. The main effects of condition, $F(1,5)=25.68, p<.01$, and display size, $F(2,10)=20.19$, $p<.01$, were significant, as was the interaction between condition and display size, $F(2,10)=7.78, p<.01$. RTs showed a larger increase with display size in the conjunction condition than in the preview condition.

Occlusion versus single-feature search. RTs increased with display size, $F(2,10)=24.84, p<.01$, but there was no significant main effect of condition, $F(1,5)=2.71, n s$; nor was there a significant interaction between condition and display size, $F(2$, 10) $=1.79, n s$.

Occlusion versus conjunction baseline. The main effects of condition, $F(1,5)=19.75, p<.01$, and display size, $F(2,10)=$ 17.54, $p<.01$, were significant. There was also a significant interaction between condition and display size, $F(2,10)=6.70, p$ $<.05$, in which RTs were faster in the preview condition than in the conjunction condition.

Preview versus occlusion. There was a reliable effect of display size, $F(2,10)=12.82, p<.01$. However there was no main effect of condition, $F(1,5)=0.27$, $n s$, nor a reliable Condition $\times$ Display Size interaction, $F(2,10)=0.96$, $n s$.

\section{Discussion}

In Experiment 3b, both the standard preview condition and the occlusion condition showed a complete preview benefit (i.e., the search slopes for both preview conditions reached that of the single-feature baseline). This suggests that all the old items were completely marked, unlike in Experiments 1-3a above, in which only a partial preview effect was observed. Why then is marking completely preserved in this experiment? One explanation is that in these conditions, there was slower apparent motion of the blocks. If fewer attentional resources were required to process the slow movements, then more resources would be available to inhibit the old items. Consequently a full preview benefit should occur. This makes sense in ecological terms. Presumably, to optimize the chances of survival, individuals must often prioritize

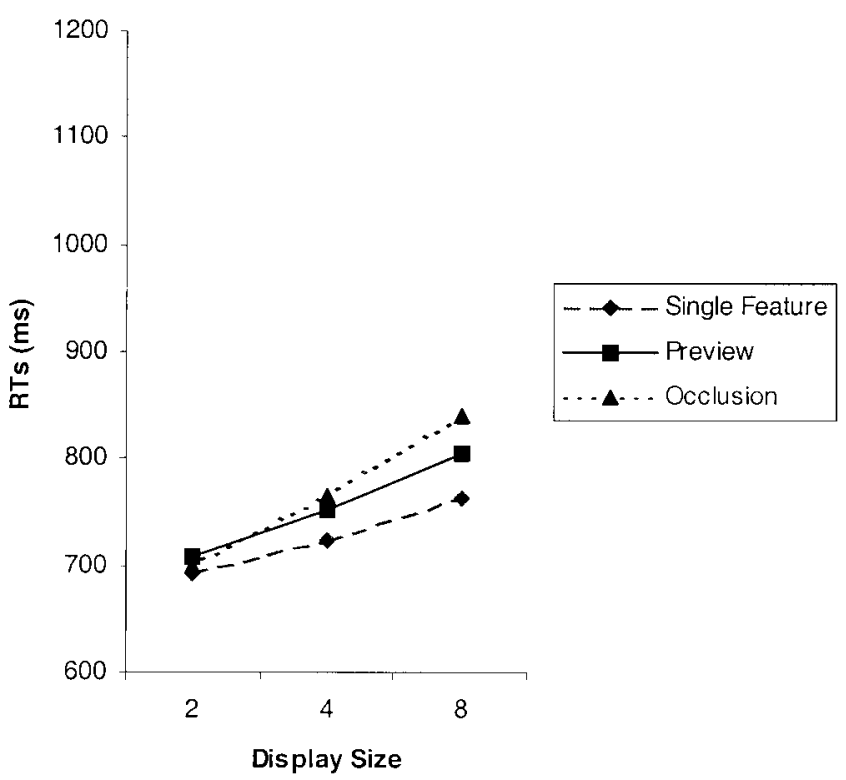

Figure 9. Mean correct reaction times (RTs) in Experiment $3 \mathrm{~b}$ for the single-feature and preview conditions. 


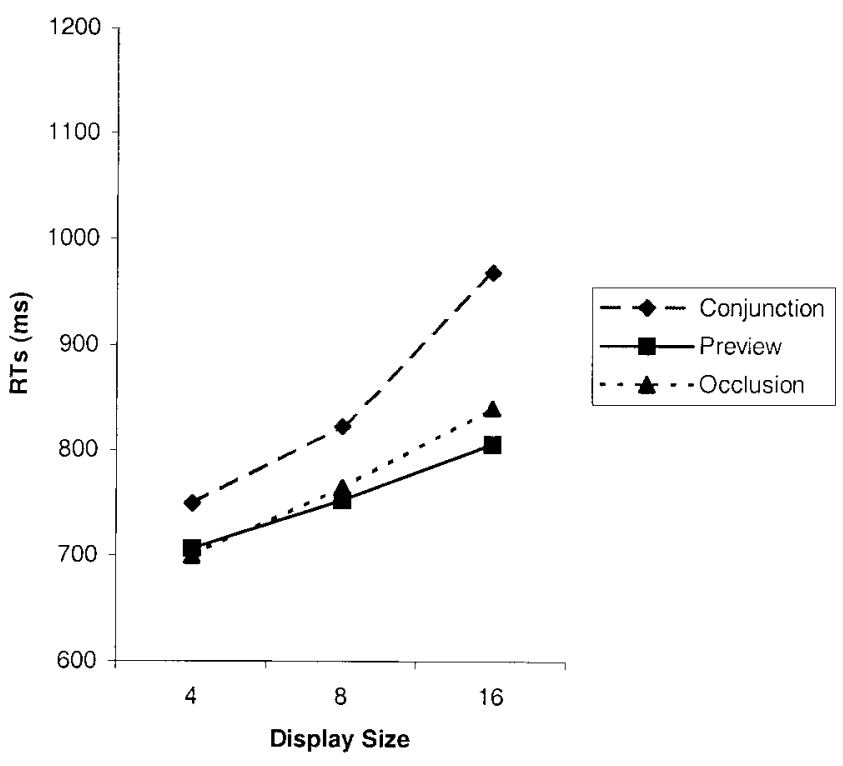

Figure 10. Mean correct reaction times (RTs) in Experiment $3 \mathrm{~b}$ for the conjunction and preview conditions.

selection to quickly moving stimuli (and less to objects moving more slowly). This would then leave fewer resources available to inhibit irrelevant stimuli, when old items move quickly.

Another important point from this experiment is that marking fully survived occlusion, even over a time period of 1,000 ms. In the General Discussion, we elaborate on the importance of this result for understanding how preview effects occur.

\section{General Discussion}

We have reported data on the preview advantage on visual search. We have shown the following: (a) A partial preview advantage occurs even when old distractors are occluded prior to the presentation of the new items (Experiments 1, 2, and 3a); (b) similar local contrast changes to those present owing to occlusion are sufficient to eliminate the preview advantage when old items offset (Experiment 2); (c) a full preview advantage is not necessarily obtained even when old items remain visible throughout a trial (Experiment 1), if there are irrelevant moving items in the display; (d) there is no effect of occlusion on the preview advantage, over and above disruption due to the presence of long-range apparent motion when old items are exposed (Experiment 1); (e) the preview advantage occurs over a number of different occlusion time periods, with occlusion of up to $1,000 \mathrm{~ms}$; and (f) a relative slowing of the speed of the apparent motion causes a complete preview advantage with old occluded items.

\section{Inhibitory Marking and Movement of the Blocks}

These results have important consequences for understanding how the preview benefit arises. The timing conditions in the study were such that the old items should capture attention when they are re-presented after occlusion (Yantis \& Gibson, 1994), if inhibition to the items was not maintained. This is particularly the case in Experiment $3 b$, in which the occlusion interval was $1,000 \mathrm{~ms}$. Despite this, our data clearly show that old items were less effective than new items in capturing attention (hence we consistently show at least a partial preview benefit, and a full benefit in Experiment $3 b$ ). Local luminance and contrast changes were also not sufficient to prevent the partial preview benefit under occlusion conditions, though the same local changes eliminated the preview advantage when the old items transiently offset from the field (Experiment 2). In this way, previewed items under various occlusion conditions maintained their identity and thus appear to remain inhibited after reappearing from "behind" the occluders. We conclude that this preview effect is dependent on relatively high-level representations of stimuli that survive occlusion but do not survive matched offset time periods.

Our results on preview effects under occlusion are consistent with an account in terms of VM (see Watson \& Humphreys, 1997). According to this account, old items are inhibited in a top-down fashion so that they subsequently do not interfere with search. The magnitude of any inhibitory effect is influenced by factors such as whether participants are engaged in other secondary tasks when old stimuli are presented. When a secondary task is imposed, either participants may fail to establish the goal of inhibiting the old distractors or the resources required for inhibition may be reduced (for further discussion of secondary task effects, see Humphreys et al., 2002; Watson \& Humphreys, 1997). In either case, inhibition effects are reduced, and old items may compete more strongly for selection with new stimuli. This can help to explain why we consistently found partial marking under the occlusion conditions in Experiments 1-3a. For instance, attention during the preview may be captured by the motion of the red blocks. Alternatively, attention may be taken away from the old distractors by the demands of computing long-range motion (Horowitz \& Treisman, 1994). In either case, there will be reduced resources available for inhibitory marking. This ties in with the results found in Experiment $3 \mathrm{~b}$, in which the apparent movement of the blocks was slowed so that fewer cognitive resources should be required to process the motion. Under these conditions and for the first time here, a full preview benefit was found.

Table 5

Descriptive Statistics for the Search Functions in Experiment $3 b$

\begin{tabular}{lcccc}
\hline \multicolumn{1}{c}{ Measure } & Single feature & Conjunction & $\begin{array}{c}\text { Standard } \\
\text { preview }\end{array}$ & $\begin{array}{c}\text { Occlusion } \\
\text { preview }\end{array}$ \\
\hline Slope (ms/item) & 5.8 & 18.3 & 8.0 & 11.4 \\
Intercept (ms) & 672 & 676 & 680 & 662 \\
Mean RT (ms) & 726 & 847 & 755 & 768 \\
\hline
\end{tabular}

Note. $\quad \mathrm{RT}=$ reaction time. 
An alternative account of the preview benefit is that it does not reflect inhibition of old items but attentional capture of new objects. At least two forms of this attentional capture account can be formulated. One, recently proposed by Donk and Theeuwes (2001), is that attention is captured in a bottom-up fashion by the new luminance increments created when the new items appear. However, our results present some difficulties for this proposal. For example, the offsets of the old stimuli, and their onsets when they reappeared, were closely matched in the offset and occlusion conditions of Experiment 2. Despite this, search was more efficient in the occlusion condition. If only onsets at the start of the search display were important, then search should have been equally disrupted in these conditions (because the old items always had onsets co-occurring with the onsets of the new items in both the offset and occlusion conditions). In addition, in Experiment $3 \mathrm{~b}$ we found a full preview benefit even with old items occluded for $1,000 \mathrm{~ms}$. This is almost a factor of 10 times the interval required for old items to be treated again as new items when re-presented in studies of onset capture (Yantis \& Gibson, 1994). In an onsetcapture account, we would again expect performance here to approximate that in the conjunction baseline. It clearly did not.

The second form of attention capture holds that it is the status of the new search stimuli as objects, rather than their being created by onsets, that is important (e.g., Yantis \& Hillstrom, 1994). For this account, the occlusion of the old items may not be crucial, provided that their (old) object status is maintained, so enabling attention to be drawn to the new items in search displays. Hence a preview benefit may be predicted across the occlusion displays. One difficulty for this account, though, is why performance should be affected by movement of the red blocks, even when they did not occlude the old distractors (e.g., Experiment 1). The moving red blocks should have no effect on the status of the old items, and yet only partial preview effects emerged (with the exception of Experiment 3, when slowed movement was examined). However, the detrimental effects of the moving blocks are consistent with a marking account, which holds that marking is less efficient when fewer resources are used to inhibit the old stimuli (Humphreys et al., 2002; Watson \& Humphreys, 1997).

\section{Why Marking Survives Occlusion}

Watson and Humphreys (1997) originally argued that the preview advantage is due to inhibition applied to the locations of old, stationary distractors (see also Olivers, Watson, \& Humphreys, 1999). Location-based inhibition could give rise to a preview benefit even when old, stationary distractors are occluded (as here), if locations are coded in three-dimensional space. For example, the occlusion relations between the blocks and the old distractor letters here could be interpreted in terms of the old letters lying in a more distant depth plane than the blocks. Inhibition applied to locations in that further depth plane could facilitate attentional selection of new letters. Note that, for this account to hold, stimuli would need to have been coded for their relative depth relations, with constancy operations perhaps also being applied; locations would not simply be coded within a twodimensional (e.g., retinal) framework.

Other research, however, indicates that forms of grouping can influence the preview benefit. An example of this is when both old and new items move in displays (e.g., see Watson, 2001; Watson
\& Humphreys, 1998). A preview benefit can emerge under these conditions, but only when the old and new distractors can be assigned to separate groups (e.g., because they have different colors). In this case, inhibition may be applied to a common feature across the group (e.g., to the color of the old set) or to the object-based representations formed for the group. This account of inhibition affected by grouping could also explain the present data, to the extent that the grouped representation is maintained (and inhibited) even when individual members are temporarily occluded. Of course, the location-based and group-based accounts of inhibitory marking are not mutually exclusive; it is possible that inhibition operates at a number of different levels in visual selection.

\section{Occlusion Relations in Search}

As well as being relevant to account for the preview benefit, the present data also speak to issues concerned with how information is coded in visual search. The results show that search can be made more efficient when occlusion relations enable old and new items to be perceptually segregated. When occlusion relations are not present but local luminance and contrast changes are, search is disrupted (Experiment 2). These findings suggest that search operates on visual representations coded for relative depth and not simply on two-dimensional retinal representations. This fits with the idea that high-level representations are rapidly assimilated in parallel across displays to influence search (e.g., see Duncan \& Humphreys, 1989; Enns \& Rensink, 1991). The data also fit with results showing that occlusion is not disruptive either to the perception of young infants (Baillargeon, 1986; Baillargeon \& DeVos, 1991; Baillargeon \& Graber, 1987; Spelke et al., 1992) or to one's ability to track moving objects (Scholl \& Pylyshyn, 1999). Apparently, the human visual system has evolved so that occlusion relations can be dealt with efficiently in object perception and tracking. Our results show that this extends to the ability to ignore old distractors in search.

\section{References}

Assad, J. A., \& Maunsell, J. (1995, February 9). Neuronal correlates of inferred motion in primate posterior parietal cortex. Nature, 373, 518521 .

Baillargeon, R. (1986). Representing the existence and the location of hidden objects: Object permanence in six- and eight-month-old infants. Cognition, 23, 21-41.

Baillargeon, R., \& DeVos, J. (1991). Object permanence in young infants: Further evidence. Child Development, 62, 1227-1246.

Baillargeon, R., \& Graber, M. (1987). Where's the rabbit? 5.5 month-old infants' representation of the height of a hidden object. Cognitive Development, 2, 375-392.

Cavanagh, P. (1991). Short-range vs. long-range motion: Not a valid distinction. Spatial Vision, 5, 303-309.

Davis, G., \& Driver, J. (1997). A functional role for illusory colour spreading in the control of focused visual attention. Perception, 26, 1397-1411.

Donk, M., \& Theeuwes, J. (2001). Visual marking beside the mark: Prioritizing selection by abrupt onsets. Perception \& Psychophysics, 93, 891-900.

Duncan, J., \& Humphreys, G. W. (1989). Visual search and stimulus similarity. Psychological Review, 96, 433-458.

Enns, J. T., \& Rensink, R., A. (1991). Preattentive recovery of three- 
dimensional orientation from line drawings. Psychological Review, 98, 335-351.

Horowitz, T., \& Treisman, A. (1994). Attention and apparent motion. Spatial Vision, 8, 193-219.

Humphreys, G. W., Watson, D. G., \& Jolicœur, P. (2002). Fractionating visual marking: Dual-task decomposition of the marking state by timing and modality. Journal of Experimental Psychology: Human Perception and Performance, 28, 640-660.

Kellman, P. J., \& Spelke, E. R. (1983). Perception of partly occluded objects in infancy. Cognitive Psychology, 15, 483-524.

Olivers, C. N., \& Humphreys, G. W. (2002). When visual marking meets the attentional blink: More evidence for top-down limited capacity inhibition. Journal of Experimental Psychology: Human Perception and Performance, 28, 22-42.

Olivers, C. N. L., Watson, D. G., \& Humphreys, G. W. (1999). Visual marking of locations and feature maps: Evidence from within-dimension defined conjunctions. Quarterly Journal of Experimental Psychology, $52 A, 679-715$.

Scholl, B. J., \& Pylyshyn, Z. W. (1999). Tracking multiple items through occlusion: Clues to visual objecthood. Cognitive Psychology, 38, $259-$ 290.

Spelke, E. S., Breinlinger, K., Macomber, J., \& Jacobson, K. (1992). Origins of knowledge. Psychological Review, 99, 605-632.

Treisman, A., \& Gelade, G. (1980). A feature-integration theory of attention. Cognitive Psychology, 12, 97-136.
Verstraten, F. A. J., Cavanagh, P., \& Labianca, A. T. (2000). Limits of attentive tracking reveal temporal properties of attention. Vision Research, 40, 3651-3664.

Watson, D. G. (2001). Visual marking in moving displays: Feature-based inhibition is not necessary. Perception \& Psychophysics, 63, 74-84.

Watson, D. G., \& Humphreys, G. W. (1997). Visual marking: Prioritizing selection for new objects by top-down attentional inhibition of old objects. Psychological Review, 104, 90-122.

Watson, D. G., \& Humphreys, G. W. (1998). Visual marking of moving objects: A role for top-down feature based inhibition in selection. Journal of Experimental Psychology: Human Perception and Performance, 24, 946-962.

Watson, D. G., \& Humphreys, G. W. (2000). Visual marking: Evidence for inhibition using a probe-dot detection paradigm. Perception \& Psychophysics, 62, 471-481.

Yantis, S., \& Gibson, B. (1994). Object continuity in apparent motion and attention. Canadian Journal of Experimental Psychology, 48, 182-204.

Yantis, S., \& Hillstrom, A. P. (1994). Stimulus-driven attentional capture: Evidence from equiluminant visual objects. Journal of Experimental Psychology: Human Perception and Performance, 20, 95-107.

Received February 5, 2001

Revision received January 17, 2002

Accepted June 21, 2002 